\title{
Hybrid approach for management of type B dissection involving the aortic arch
}

\author{
Pradeep Narayan ${ }^{1}$, Shreyas Potdar ${ }^{1}$, Shuvro Roy Choudhury ${ }^{2}$, Atanu Saha ${ }^{1}$ \\ ${ }^{1}$ Department of Cardiac Surgery, NH Rabindranath Tagore International Institute of Cardiac Sciences, Kolkata, India \\ ${ }^{2}$ Department of Intervention Radiology, NH Rabindranath Tagore International Institute of Cardiac Sciences, Kolkata, India
}

Kardiochirurgia i Torakochirurgia Polska 2019; 16 (1): 42-43

Acute type B aortic dissections can be treated medically, surgically as well as by thoracic endovascular stents (TEVAR). However, presentations and pathology can vary and an isolated strategy may not be adequate in managing the condition satisfactorily. We describe a hybrid approach using surgery and endovascular stents to adequately manage type $B$ dissection in a 76-year-old man, a known hypertensive and chronic smoker who presented to the emergency department with acute retrosternal pain radiating to the neck and back. The patient had intractable pain and refractory hypertension despite optimal medical therapy. Echocardiography showed a large subclavian atheromatous flap. Computed tomography (CT) scan confirmed type B aortic dissection (Fig. 1). In view of the patient being elderly, hypertensive and a chronic heavy smoker, surgical repair was considered to be associated with high risk. As the pathology extended up to the left subclavian artery, endovascular stent placement with a sufficient landing zone would have required occlusion of the left carotid artery. A decision was therefore taken to perform a carotico-carotid bypass and an endovascular stent to treat the type B aortic dissection.

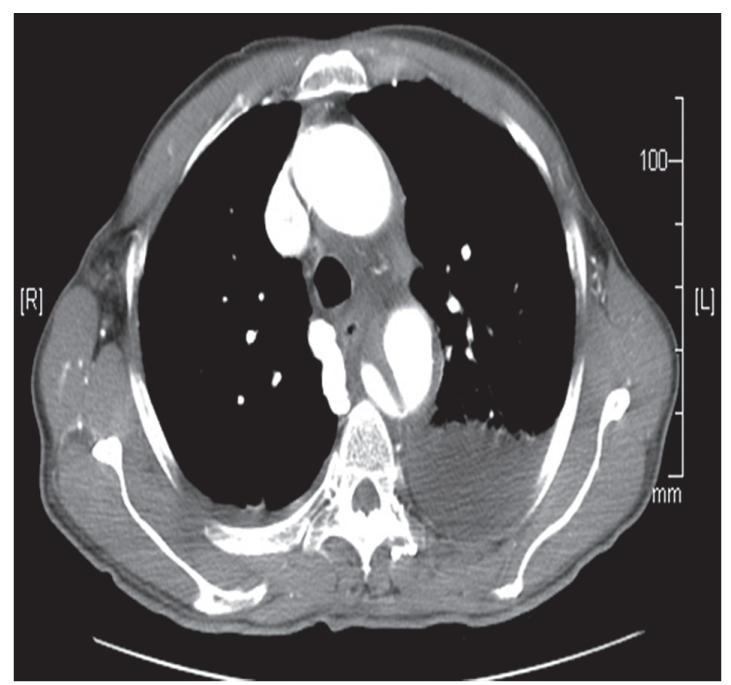

Fig. 1. Pre-operative computed tomography image showing type $B$ dissection
The carotico-carotid bypass preceded the endovascular stent placement. End-to-side $8 \mathrm{~mm}$ PTFE grafts were anastomosed to the right and left carotid artery using 6-0 prolene suture with partial cross clamp. Neurological status was monitored throughout the procedure with the Symantec monitoring system. Following the completion of the carotico-carotid bypass the left subclavian artery was coiled with $1 \times 20 \mathrm{~mm} \times 8 \mathrm{~cm}$ and $2 \times 14 \mathrm{~mm} \times 8 \mathrm{~cm}$ Nestor coils to prevent future leaks. A Cook Zenith TX -2 thoracic endograft (36/20-2 mm) was implanted in the descending thoracic aorta with the proximal landing zone extending to the origin of the left subclavian artery. Procedural CT angio showed a satisfactory position of the endovascular stent and no endoleaks. Also the carotico-carotid bypass was confirmed to be patent (Fig. 2).

The patient was extubated on the first postoperative day (POD) without any neurologic deficit. The postoperative course was uneventful and the patient was discharged from the hospital in a stable and improving condition. At 6 months follow-up the patient remains well with no neurological deficits.

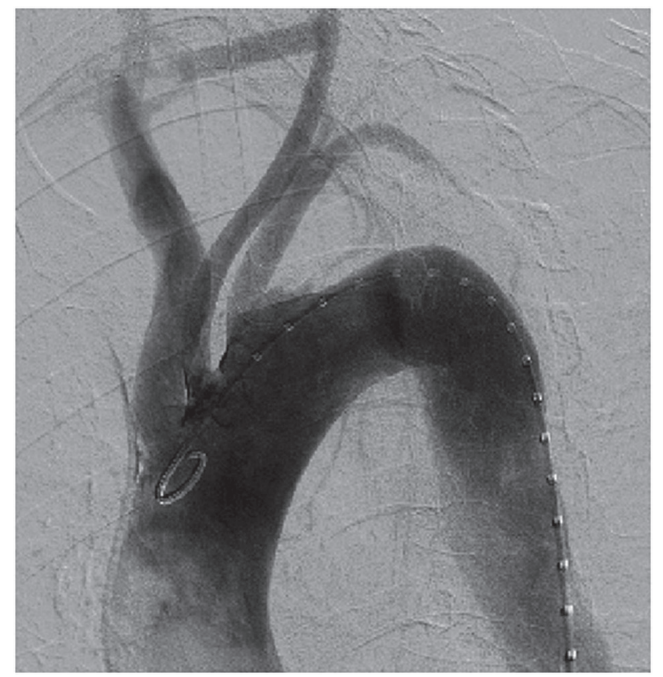

Fig. 2. Computed tomography angiogram confirming absence of endoleak and patent carotico-carotid bypass

Address for correspondence: Pradeep Narayan, Department of Cardiac Surgery, NH Rabindranath Tagore International Institute of Cardiac Sciences, 700094 Kolkata, India, phone: +91 8017249115, e-mail: pradeepdoc@gmail.com

Received: 4.09.2018, accepted: 13.12.2018. 
Surgical repair of acute type B aortic dissection is associated with higher mortality compared to TEVAR $(17.5 \%$ vs. $10.2 \%)$ especially in the case of elderly patients [1]. Age $>70$ years has been shown to be an independent predictor of increased surgical mortality for open surgical repair [2].

The TEVAR is therefore preferred in the management of acute type $B$ dissections in the elderly. However, TEVAR alone may not be possible in all cases as it requires an adequate landing zone. As in our case, in about a quarter of patients with type B aortic dissection, the aortic arch is involved due to retrograde propagation, and often necessitates the proximal anchoring zone to extend up to the aortic arch. In these situations we require a hybrid procedure that involves combined supra-aortic debranching techniques and TEVAR and has shown to be a promising option to avoid open surgery in such challenging anatomies [3].

For a hybrid procedure to be successful it is important to evaluate and stratify the landing zone using the Ishimaru and Mitchell classification [4]. The zone stratification is important as outcomes differ depending on the affected zone. Hybrid repair in zones 1 and 2 appears a viable alternative to conventional aortic arch surgery in patients with complicated type B aortic dissection. However, hybrid repair in zone 0 in a recent review was associated with a mortality rate that was three times higher than repair involving zones 1 and 2 [3]. The rate of neurologic complications decreases with time and experience. It is also influenced by centre volume and may be low in dissection cases; however, durability over the longer term remains to be evaluated [3].

Extra-anatomic arch reconstruction is the surgical component of the hybrid repair and can be performed safely and appears to be durable over long-term follow-up. Its use with endovascular grafting should provide a durable reconstruction for patients who require aortic "debranching" prior to endovascular thoracic aortic aneurysm repair.
The technique of supra-aortic vessels debranching is also influenced by the zones involved. For Zone 1 as in our case, extra-anatomical revascularization of the left common carotid artery can be performed. "Zone 0" cases require revascularization of the brachiocephalic trunk and left common carotid artery from the ascending aorta. And in "zone 2" intentional covering of the left subclavian artery without revascularization can also be performed [5].

Hybrid repair, as in this case, provides another option for management of type B aortic pathologies with extension to the aortic arch. In the elderly and frail where an open repair is deemed prohibitively risky, hybrid repair appears promising.

\section{Disclosure}

The authors report no conflict of interest.

\section{References}

1. Fattori R, Cao P, De Rango P, Czerny M, Evangelista A, Nienaber C, Rousseau H, Schepens $M$. Interdisciplinary expert consensus document on management of type B aortic dissection. J Am Coll Cardiol 2013; 61: 1661-1678.

2. Trimarchi S, Nienaber CA, Rampoldi V, Myrmel T, Suzuki T, Bossone E, Tolva V, Deeb MG, Upchurch GR Jr, Cooper JV, Fang J, Isselbacher EM, Sundt TM $3^{\text {rd }}$, Eagle KA; IRAD Investigators. Role and results of surgery in acute type B aortic dissection: insights from the International Registry of Acute Aortic Dissection (IRAD). Circulation 2006; 114 (Suppl I): I-357-I-364.

3. Cao P, De Rango P, Czerny M, Evangelista A, Fattori R, Nienaber C, Rousseau H, Schepens M. Systematic review of clinical outcomes in hybrid procedures for aortic arch dissections and other arch diseases. J Thorac Cardiovasc Surg 2012; 144: 1286-1300

4. Mitchell RS, Ishimaru S, Ehrlich MP, Iwase T, Lauterjung L, Shimono T, Fattori R, Yutani C. First International Summit on Thoracic Aortic Endografting: roundtable on thoracic aortic dissection as an indication for endografting. J Endovasc Ther 2002; 9 (Suppl 2): ॥98-II105.

5. Melissano G, Civilini E, Bertoglio L, Calliari F, Setacci F, Calori G, Chiesa R. Results of endografting of the aortic arch in different landing zones. Eur J Vasc Endovasc Surg 2007; 33: 561-566. 